\title{
PENINGKATAN KAPASITAS KOMUNITAS PARIWISATA DESA TENTANG PARIWISATA KREATIF DI BELITUNG TIMUR
}

\author{
Ayu Krishna Yuliawati ${ }^{1)}$, Budhi Pamungkas Gautama ${ }^{2)}$, Rofi Rofaida ${ }^{3)}$, \\ Shandra Rama Panji Wulung ${ }^{4)}$, Asti Nur Aryanti ${ }^{5)}$ \\ 1, 2, 3,4) Universitas Pendidikan Indonesia, Bandung, Indonesia \\ ${ }^{5)}$ STIE INABA, Bandung, Indonesia \\ E-mail: ayukrishna@upi.edu,budhipamungkas@upi.edu,rofi.rofaida@upi.edu, \\ wulung@upi.edu, astinuraryanti@gmail.com
}

\begin{abstract}
ABSTRAK
Peran pengembangan pariwisata pedesaan dapat membantu mempromosikan dan membantu masyarakat setempat Desa Sebunyuk. Tujuan kegiatan ini adala untuk mengidentifikasi kebutuhan dan permasalahan dalam pengembangan Sebunyuk sebagai Desa Wisata. Mitra kegiatan ini adalah komunitas penggerak pariwisata di Nam Pit Salu, Desa Sebunyuk. Permasalahan utama pola pikir masyarakat yang masih memiliki mindset sebagai buruh tani atau penambang dan belum melihat usaha pariwisata sebagai bidang yang menguntungkan masyarakat desa di masa depan. Permasalahan mitra diatasi melalui peningkatan kapasita serta pendampingan dalam penerapan tata kelola organisasi,terutama pada aspek manajemen dan pemasaran produk pariwisata kreatif.
\end{abstract}

Kata Kunci: Pariwisara Kreatif, Desa Wisata, Pemberdayaan Masyarakat, Belitung Timur

\section{ABSTRACT}

The role of rural tourism development can help promote and help the local community of Sebunyuk Village. The purpose of this activity is to identify the needs and problems in developing Sebunyuk as a Tourism Village. The activity partner is the tourism community in Nam Pit Salu, Sebunyuk Village. The main problem is the mindset of people who still have a mindset as farm laborers or miners and do not see tourism as a field that benefits rural communities in the future. Partner problems are overcome through capacity building and assistance in implementing organization management, especially in management and marketing creative tourism products.

Key words: Creative Tourism, Tourist Village, Village Community Empowerment, Belitung Timur 


\section{PENDAHULUAN}

Sektor industri pariwisata dalam membangun desa, dijadikan sebagai alternatif sektor dalam meningkatkan kesejahteraan ekonomi masyarakat desa. Pariwisata pedesaan menjadi produk yang berpotensi dalam mempromosikan suatu wilayah yang melibatkan peran masyarakat setempat dalam pembangunannya. Lebih lanjut, wisata pedesaan muncul sebagai solusi bagi penanganan dampak negatif dari aktivitas wisata masal bagi negara-negara berkembang dan merupakan salah satu strategi bagi masyarakan untuk mencapai kondisi kehidupan yang lebih baik (Amir dkk., 2015).

Gagasan utama pariwisata pedesaan adalah mengupayakan masyarakat setempat dalam mengembangkan suatu kegiatan yang menghadirkan pembangunan berkelanjutan dan mempromosikan hubungan antar masyarakat setempat dengan wisatawan. Pengembangan produk wisata harus mampu mengintegrasikan antara industri pariwisata (hotel, layanan makan dan minuman, biro perjalanan wisata), infrastruktur, lingkungan, kesehatan, hingga pendidikan menjadi suatu sistem kepariwisataan (Peng dan Lin, 2016). Pengembangan daya tarik wisata di wilayah pedesaan menjadi hal yang pertama diidentifikasikan untuk meningkatkan daya saing destinasi dan mendorong kunjungan wisatawan (Butler, 2017).

Di Indonesia, khususnya di Pulau Belitung, sektor pariwisata dijadikan sebagai upaya meningkatkan ekonomi masyarakat setempat. Kawasan pedasaan menjadikan pariwisata sebagai solusi yang layak karena memanfaatkan aset alam dan budaya daearh sebagai daya tarik utamanya (Chok dkk.,2007; Huang dkk., 2016; Oppermann, 1996).

Berbagai dukungan pemerintah dalam mengembangkan wilayah pedesaan sebagai destinasi pariwisata melalui berbagai program-program dan pembinaan, program bantuan PNPM Mandiri wisata, sehingga program ini diharapkan mampu meningkatkan kesejahteraan masyarakat.

Pulau Belitung telah ditetapkan menjadi salah satu taman bumi (geopark) nasional pada akhir tahun 2017 sebagai wujud dari pariwisata pulau kecil. Tindak lanjut dari penetapan Geopak Pulau Belitong salah satunya adalah pembentukan Badan Pengelola Geopark Pulau Belitong melalui Peraturan Bersama Bupati Belitung dan Bupati Belitung Timur Nomor 8 Tahun 2017 dan Nomor 9 Tahun 2017.

Untuk meningkatkan pembangunan berkelanjutan di Geopark Pulau Belitung, diperlukan upaya bersama melalui integrasi lintas sektor dan peran serta keterlibatan pemangku kepentingan. Pengembangan potensi wisata di Kabupaten Belitung Timur difokuskan pada pembangunan desa wisata, hal tersebut bertujuan untuk mengangkat dan melindungi nilai-nilai budaya, agama, adat istiadat, optimalisasi potensi ekonomi dan karakteristik daerah. Mengingat pilar dasar dari geopark adalah keragaman geologi, keragaman hayati, dan keragaman budaya (Brilha, 2018; Ólafsdóttir dan Dowling,2014; UNESCO, 2016).

Pembangunan pariwisata pedesaan suatu daerah memiliki lima tujuan utama (Lane, 1994), mencakup: 1) mempertahankan budaya dan karakter masyarakat setempat; 2) melestarikan lanskap dan habitat; 3) mempertahankan ekonomi pedesaan; 4) mempertahankan industri pariwisata yang akan bertahan dalam jangka panjang; dan 5) mengambangkan pemahaman, kepemimpinan, dan visi yang memadai di antara para pembuat kebijakan. Tujuan- tujuan pengembangan pariwisata pedesaan tersebut memiliki persamaan visi dengan dibangunnya Geopark Pulau Belitong. Melalui pengembangan 
pariwisata pedesaan diharapkan dapat membantu menjaga keragaman hayati dan budaya serta geologi yang dijadikan sebagai daya tarik wisata unggulan di Geopark Pulau Belitong.

Salah satu pengembangan destinasi wisata di Pulau Belitong yang mampu menjadi daya tarik wisatawan adalah Open Pit Nam Salu yang terletak pada Desa Senyubuk, Kecamatan Kelapa Kampit, Belitung Timus. Pada beberapa literatur terdahulu terungkap beberapa konsep dan pendekatan dalam meningkatkan potensi daerah khususnya pada peningkatan dan penciptaan potensi desa pada sektor wisata, beberapa konsep yang dapat digunakan yaitu konsep peningkatan potensi wisata berbasis komunitas.

Adapun hambatan yang terjadi dalam desa tersebut berupa pola pikir masyarakat yang masih berfikiran menjadi buruh tani dan belum melihat usaha pariwisata sebagai alat yang menguntungkan desa mereka di masa depan. Mental sebagai pencari kerja dan bukan sebagai wirausaha pariwisata kreatif, tingkat pendidikan warga Desa Senyubuk yang rendah dan juga belum tersosialisasikan Sapta Pesona dengan baik serta potensi Open Pit Nam Salu di Desa Senyubuk. Pengabdian kepada masyarakat ini memiliki sasaran utama untuk meningkatkan pembangunan ekonomi daerag Geopark Pulau Belitung melalui identifikasi kebutuhan dan permasalahan dalam pengembangan Desa Wisata Sebunyuk.

Tujuan pelaksanaan pengabdian kepada masyarakat dengan tema pemberdayaan masyarakat desa melalui pariwisata kreatif berbasis komunitas, adalah sebagai beirkut:

- Meningkatkan pemahaman dan pengetahuan masyarakat dan pemangku kepentingan kepariwisataan terhadap pariwisata kreatif

- Meningkatkan kapasitas dan pengetahuan pengelola pariwisata dalam merancang produk pariwisata kreatif di desanya

\section{TINJAUAN PUSTAKA}

Pemberdayaan masyarakat (Hadiwijoyo, 2012:28-32) adalah suatu proses yang berjalan terus menerus dalam meningkatkan kemampuan dan kemandirian masyarakat serta meningkatkan taraf hidupnya. Pemberdayaan masyarakat kerap kali dilakukan melalui pendekatan kelompok, di mana anggota kelompok bekerjasama dan berbagi.Salah satu bentuk pemberdayaan masyarakat adalah melalui pemanfaatan sektor yang potensial, yakni pariwisata kreatif untuk menjadikannya desa wisata.

Nurhidayati (Hadiwijoyo, 2012 : 83) sebagaimana dikutip oleh Gde Satrya (2010) mendefinisikan Community Based Tourism (CBT) sebagai:1) bentuk pariwisata yang memberikan kesempatan kepada masyarakat lokal untuk mengontrol dan terlibat dalam manajemen dan pembangunan pariwisata. 2)memberikan keuantungan kepada masyarakat yang tidak terlibat langsung dalam usaha-usaha pariwisata. 3) menuntut pemberdayaan secara politis dan demokratisasi dengan distribusi keuntungan kepada komunitas yang kurang beruntung di pedesaan.

Jadi intinya, CBT merupakan perwujudan perluasan dampak sektor pariwisata pada pembangunan perekonomian lokal (local economic development) masyarakat di sekitar kawasan wisata. Program ini memberikan peluang kepada masyarakat untuk mendapatkan pekerjaan dan kesempatan berwirausaha di sektor pariwisata secara lebih luas.

Produk pariwisata secara lokal diartikulasikan dan dikonsumsi, produk wisata dan konsumennya harus visible bagi penduduk lokal yang seringkali sangat sadar terhadap dampak turisme. Sehubungan dengan hal tersebut, maka pariwisata harus melibatkan 
masyarakat lokal, sebagai bagaian dari produk turisme, selain itu, dari pihak industri juga harus melibatkan masyarakat lokal dalam pengambilan keputusan. Sebab, masyarakat lokal yang harus menanggung dampak kumulatif dari perkembangan wisata dan mereka butuh untuk memiliki input yang lebih besar, bagaimana masyarakat dikemas dan dijual sebagai produk pariwisata (Murphy dalam Hadiwijoyo, 2012 : 87).

Pariwisata kreatif menurut UNESCO adalah "perjalanan yang bertujuan untuk mendapatkan pengalaman yang otentik dengan pembelajaran partisipatif dalam seni, heritage, atau karakter khusus suatu tempat, yang menghasilkan keterkaitan dengan masyarakat di tempat tersebut yang menciptakan budaya tersebut" (travel directed toward an engaged and authentic experience, with participative learning in the arts, heritage or special character of a place, and it provides a connection with those who reside in this place and craete this living culture- UNESCO Creative Cities Network, 2006).

\section{METODE PELAKSANAAN}

Pendekatan pada kegiatan pengabdian kepada masyarakat ini menggunakan metode penyuluhan berupa transfer ilmu pengetahuan kepada mitra dan pendampingan. Pengumpulan data melalui data sekunder (artikel jurnal, laporan, halaman web organisasi, dan dokumen kebijakan) dan data primer (survei lapangan, focus group discussion, dan wawancara).

Penyuluhan dan pendampingan dilakukan dimulai dengan memberikan pengetahuan dan pemahaman dasar-dasar tentang keanekaragaman sumber daya pariwisata dan integrasinya dengan industri jasa pariwisata. Selain itu dilakukan penyu juga pemaparan tentang pengintegrasian antara Badan Usaha Milik Desa (BUMDES), pariwisata kreatif, dan berbagai produk hasil masyarakat desa.

Rencana kegiatan yang merupakan langkah-langkah solusi dapat dikelompokkan menjadi beberapa tahapan, mencakup 1)tahap persiapan, pemetaan potensi wisata desa binaan; 2) tahap inisiasi: proses analisa potensi desa wisata; 3) tahap implementasi tindakan pelaksanaan penyuluhan dan pendampingan komunitas desa wisata; dan 4)tahap monitoring dan evaluasi. Pada setiap tahapan diatas dosen bekerjasama dengan pemerintah, Badan Pengelola Geopark Belitung dan tokoh masyarakat.

\section{HASIL DAN PEMBAHASAN}

Desa Senyubuk yang merupakan salah satu dari 6 (enam) desa dari Kecamatan Kelapa Kampit dengan luas wilayah mencapai $69,90 \mathrm{~km}^{2}$ atau sekitar 14,05\% dari luas wilayah Kecamatan Kelapa Kampit. Jumlah penduduk pada tahun 2017 mencapai 3.981 juta jiwa dengan pembagian sebesar 2.000 jiwa berjenis kelamin laki-laki dan 1981 jiwa berjenis kelamin perempuan.

Open Pit Nam Salu, sebagai salah satu daya tarik wisata unggulan di Desa Sebunyuk,merupakan suatu kawasan bekas tambang terbuka dan merupakan bekas tambang timah primer terbesar di Pulau Belitong. Pengembangan kawasan tersebut tidak hanya terfokus pada daya tarik wisata, tetapi meliputi daya pembangunan prasarana, penyediaan fasilitas umum, pembangunan fasilitas pariwisata dan pemberdayaan masyarakat. Model pengembangan yang dipakai dalam pengembangan wisata perdesaaan atau desa wisata adalah model pengembangan yang bertumpu pada masyarakat local (community based tourusm) 
yang menghasilkan produk pariwisata. Dalam model ini masyarakat bukan lagi sebagai obyek, melainkan juga sebagai subyek yang terlibat aktif mulai dari perencanaan, pelaksanaan dan monitoring. Model pengembangan ini sangat sesuai untuk karakter atau jenis obyek dan daya tarik wisata yang bertumpu pada sumber daya wisata yang berhubungan langsung dengan masyarakat lokal, seperti yang dikembangkan dalam wisata pedesaan

Berdasarkan hasil observasi dan wawancara, Open Pit Nam Salu memiliki terowongan sepanjang $676 \mathrm{~m}$ dan empat area persimpangan (stopping area). Masing- masing area persimpangan memiliki kedalaman yang beragam. Pemanduan bagi wisatawan sangat disarankan dalam aktivitas penelusuran terowongan. Pengelola daya tarik wisata menarapkan sistem pembatasan waktu bagi setiap wisatawan yang berkunjung. Bagi wisatawan nusantara dilakukan 2 jam pemanduan, sedangkan wisatawan mancanegara menghabiskan 3 jam pemanduan. Selain itu, pengelola menerapkan standarisasi khusus bagi wisatawan yang ingin menelusuri terowongan, yaitu wisatawan diwajibkan memiliki kondisi fisik prima (tidak fobia gelap, fobia ruang sempit, dan fobia kelelawar). Selain pemanduan wisata, terdapat fasilitas makan dan minum yang berjarak 93 m dengan waktu tempuh berkisar 20 menit dari dasar tambang.

Pemanduan wisata yang dilakukan oleh para pemuda setempat menjadi salah satu potensi yang dapat dikembangkan di Open Pit Nam Salu. Pedampingan dan penyuluhan pemanduan dan interpretasi terkait pengetahuan produk, khususnya ilmu geologi dan manajemen pariwisata, sangat diperlukan dalam pengembangan soft skill pemandu dan pengelola destinasi ini yaitu komunitas pariwisata Nam pit salu. Hal tersebut bertujuan selain memperkaya wawasan para pemandu, pengelola/komunitas juga dapat meningkatkan kepuasan wisatawan yang berkunjung.

Focus Group Discussion (FGD) dilakukan dengan komunitas pariwisata Desa Sebunyuk untuk mengetaui hambatan dan potensi dari wilayah ini. Diketahui bahwa permasalahan yang terjadi pada komunitas pariwisata adalah: 1)Kurangnya kapasitas dan pengetahuan pemandu wisata dan komunitas untuk menjadi interpreter yang baik bagi destinasinya, 2)Belum adanya paket wisata kreatif yang edukatif yang mengintegrasikan semua destinasi pawisata di Belitung Timur,sehingga perlu dibuat. 3) Belum adanya paket masterplan pariwisata per destinasi sehingga perlu dilakukan pendampingan lebih lanjut.

Disamping itu, kegiatan pengabdian masayrakat dilakukan melalui pendampingan dan penyuluhan. Seperti yang ditunjukan pada gambar berikut.

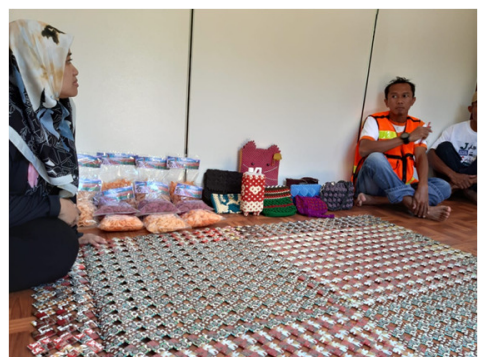

Gambar 1. Kegiatan FGD pariwisata kreatif

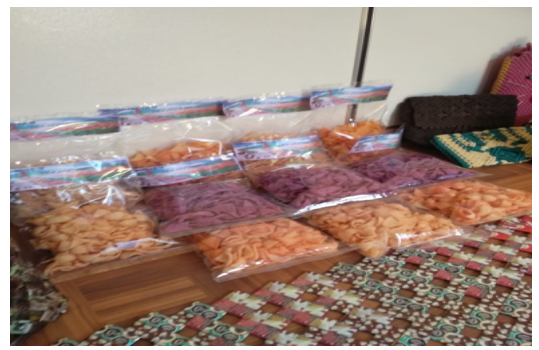

Gambar 2. Produk usaha kreatif 


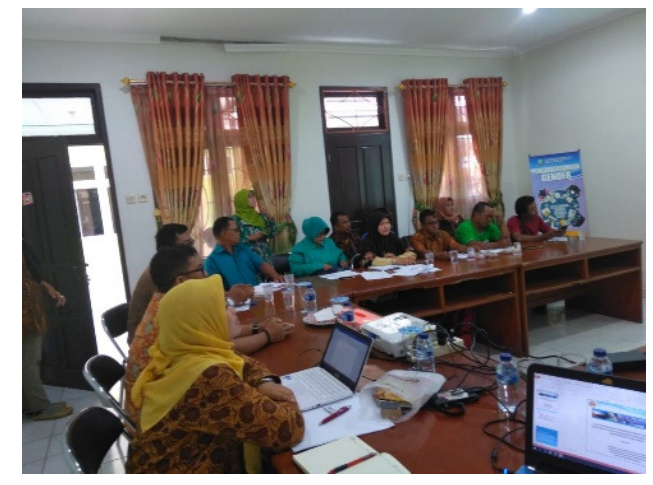

Gambar 3. Penyuluhan pariwisata kreatif di BAPPEDA Kabupaten Belitung Timur untuk Komunitas

Pendampingan yang dilakukan adalah tentang pariwisata kreatif dan produk/ jasa pariwisata kreatif yang dapat dibuat masyarakat setempat. Hal ini mengingat masyarakat sangatlah dibutuhkan dalam mengembangkan potensi pariwisata, dimana Desa Sebunyuk merupakan bagian dari Geopark Pulau Belitong. FGD kedua adalah mengenail pariwisata kreatif mengeksplor paket-paket pariwisata yang bisa ditawarkan pada wisatawan, serta produk=produk buatan masyarakat desa setempat yang dapat dijadikan penunjang kegiatan pariwisata.

Berbagai kreatif produk yang berpotensi untuk dijadikan oleh-oleh diantaranya Ubi Jalar dan kerajinan tangan setempat (tikar, topi, sejadah, hingga kotak tisu). Keterampilan tersebut didapatkan secara otodidak. Sejauh ini, pelatihan yang telah dilakukan di Desa Sebunyuk, terkait pengembangan sumber daya manusia pariwisata, mencakup pemanduan dan paket- paket wisata. Lebih lanjut, masyarakat setempat Desa Sebunyuk membutuhkan pelatihan tata kelola organisasi dan pengembangan pasar. Hal tersebut diindikasikan dengan adanya informasi tidak terdistribusikan dengan baik.

Penyuluhan pariwisata dilakukan pada tanggal 18 Juli 2019 di ruang rapat Bappeda Belitung Timur, yang dihadiri oleh: Camat, kepala desa dan komunitas pariwisata desa Senyubuk dan juga 4 desa wisata lainnya kabupaten Belitung Timur. Materi yang dibawakan adalah mengenai pariwisata kreatif, produk pariwisata dan interpretasi dari sumber daya pariwisata yang ada di desa wisata Belitung Timur. Permasalahan yang terjadi di setiap desa adalah rendahnya mindset masyarakat tentang pariwisata, hal ini dikarenakan terbatasnya pengetahuan pariwisata masyarakat dan juga dampak pariwisata terhadap ekonomi mereka tidak langsung, beda dengan kalau mereka bekerja ditambang. Pemerintah juga memiliki keterbatasan dalam hal anggaran sehingga tidak bisa mendampingi terus menerus dalam proses peningkatkan kapasitas sumber daya manusia pariwisata di desa dan pembuatan paket produk pariwisata kreatif. Kegiatan evaluasi dilakukan dengan responden berupa komunitas pariwisata Nam Pit Salu melalui keiatan FGD evaluasi dimana mereka ditanyakan apa kegaitan ini bermanfaat, harapan kegiatan kedepan dan kompetensi apa yang diperlukan ke depan ntuk mengelola destinasi pawisata ini. Hasil evaluasi responden sebanyak 10 orang yang terdiri dari pengelola destinasi, komunitas dan tokoh masyarakat menyatakan bahwa kegiatan ini sangat bermafaat, harapannya kedepan bisa dilanjutkan kegiatan dengan fokus pada pengelolaan organisasi dalam hala manajemen keunagan dan 
manajemen pemasaran, dan pengembangan produk pariwisata desa.

\section{KESIMPULAN}

Penyuluhan dan pendampingan komunitas pariwisata, terutama pemasaran produk pariwisata, menjadi salah satu hal yang dibutuhkan oleh masyarakat setempat di Desa Sebunyuk. Peningkatan pengetahuan dan kemampuan mitra dalam penerapan pemasaran pariwisata kreatif menjadi kebutuhan mendesak, Hal tersebut disebabkan kurangnya informasi yang didapatkan wisatawan dan info tidak terdistribusikan dengan baik. Selain itu, pelatihan sumber daya pariwisata dalam hal pariwisata kreatif dibutuhkan komunitas wisata di Open Pit Nam Salu. Pengelolaan destinasi tersebut selama ini dibantu oleh pemandu wisata yang bermodalkan kemampuan otodidak. Kedepannya pendampingan dan penyulihan lanjutan bagi mitra dan mayarakat Desa Sebunyuk menjadi bagian penting dari pengembangan Sebunyuk sebagai salah satu desa wisata yang memiliki daya saing tinggi.

Peranan komunitas menjadi strategis dalam upaya pengembangan pariwisata di wilayah ini. Komunitas dapat bersinergi dengan masyarakat lokal dalam mendorong produk pariwisata kreatif dalam menunjang peningkatan pariwisata kreatif. Komunitas juga dapat menjadi perantara antara masyakarat lokal dengan pihak lainnya.

\section{DAFTAR PUSTAKA}

[1]. Amir, A. F., Ghapar, A. A., Jamal, S. A., dan Ahmad, K. N. 2015. Sustainable Tourism

[2]. Development: A Study on Community Resilience for Rural Tourism in Malaysia. []. Procedia Social and Behavioral Sciences, 168: 116-122.

[3]. Brilha, J. 2018. Geoheritage and Geoparks. Geoheritage. 2018:323-335.

[4]. Butler, G. 2017. Fostering Community Empowerment and Capacity Building

[5]. through Tourism: Perspectives from Dullstroom, South Africa. Journal of Tourism and Cultural Change, 15(3): 199-212.

[6]. Chok, S., Macbeth, J., dam Warren, C. 2007. Tourism as a Tool for Poverty

[7]. Alleviation: A Critical Analysis of 'Pro-Poor Tourism' and Implications for

[8]. Sustainability. Current Issues in Tourism, 10(2-3):144-165.

[9]. Huang, W.-J., Beeco, J. A., Hallo, J. C., \& Norman, W. C. 2016. Bundling attractions for Rural Tourism Development. Journal of Sustainable Tourism, 24(10): $1387-1402$.

[10]. Lane, B. 1994. Sustainable Rural Tourism Strategies: A Tool for Development and

[11]. Conservation. Journal of Sustainable Tourism, 2(1-2): 102- 111.

[12]. Ólafsdóttir, R dan Dowling, R. 2014. Geotourism and Geoparks - A Tool for

[13]. Geoconservation and Rural Development in Vulnerable Environments: A Case Study from Iceland. Geoheritage, 6(1): 71-87.

[14]. Oppermann, M. 1996. Rural tourism in Southern Germany. Annals of Tourism Research, 23(1): 86-102.

[15]. Peraturan Bersama Bupati Belitung dan Bupati Belitung Timur Nomor 8 Tahun 2017 dan Nomor 9 Tahun 2017.

[16]. Peng, K.-L., dan Lin, P. M. C. 2016. Social Entrepreneurs: Innovating Rural Tourism through the Activism of Service Science. International Journal of Contemporary 
Hospitality Management, 28(6): 1225-1244.

[17]. UNESCO. 2016. UNESCO Global Geoparks: Celebrating Earth Heritage, Sustaining Local Communities. https://unesdoc.unesco.org/ark:/48223/pf0000243650 